\title{
PARTISIPASI MAYARAKAT DALAM PENGELOLAAN LINGKUNGAN KAWASAN HUTAN MANGROVE TUGUREJO DI KOTA SEMARANG
}

\author{
Diarto*, Boedi Hendrarto**, Sri Suryoko*** \\ * Magister Ilmu Lingkungan, Universitas Diponegoro, Semarang, Indonesia, Email: diarto.sutono@yahoo.com \\ **Faculty of Fisheries and Marine Science, Universitas Diponegoro, Semarang, Indonesia \\ ***Faculty of Political Science, Fisheries and Marine Science, Universitas Diponegoro, Semarang, Indonesia
}

\begin{abstract}
ABSTRAK
Potensi dan keunikan sumber daya alam pada Kawasan Hutan Mangrove Tugurejo (KHMT) memiliki peran sangat signifikan dalam pengembangan ekonomi, sosial, budaya, dan lingkungan masyarakat pesisir. Pengelolaan lingkungan KHMT merupakan salah satu upaya dalam mendukung pengembangan wilayah pesisir secara optimal, bijaksana, dan bertanggung jawab, tentunya dengan melibatkan partisipasi masyarakat dan berbagai pihak yang terkait serta dengan tetap memperhatikan daya dukung lingkungan KHMT. Tujuan dalam penelitian ini adalah untuk memberikan gambaran mengenai partisipasi masyarakat terhadap pengelolaan lingkungan KHMT. Antusiasme, keinginan, dan harapan serta adanya kepedulian sosial masyarakat setempat merupakan bentuk partisipasi masyarakat dalam upaya pengelolaan lingkungan KHMT. Adanya partisipasi masyarakat menjadi faktor pendukung dalam upaya pengembangan wilayah pesisir Kota Semarang. Gambaran partisipasi masyarakat terhadap pengelolaan lingkungan KHMT ditunjukkan dengan tingginya keinginan masyarakat untuk menjaga dan melestarikan serta adanya harapan terhadap upaya perlindungan atau perbaikan KHMT. Bentuk partisipasi masyarakat adalah partisipasi sukarela atau swakarsa.
\end{abstract}

Kata Kunci: Kawasan hutan mangrove tugurejo, Pengelolaam lingkungan, Partisipasi masyarakat

\begin{abstract}
The potency and uniqueness of natural resources in Mangrove Forest Area of Tugurejo (KHMT) has a very significant role in developing economic, social, cultural, and environmental of coastal communities. Environmental Management of KHMT is one of effort to support the developing coastal areas optimally, wisely, and responsibly, of course, with the community participation and other stakeholders and also by considering the carrying capacity of KHMT. The objective of this research was to provide an overview of community participation to environmental management of KHMT. The enthusiasm, desires, and expectations as well as the social concerns of local communities was a form of community participation in environmental management of KHMT. The community participation become a contributing factor in developing the coastal area of Semarang City. The overview of community participation to environmental management of KHMT was indicated by strong desire of the communities to maintain and preserve it and also the presence of community expectation for the protection or improvement of KHMT. The form of community participation was voluntary or spontaneous participation.
\end{abstract}

Keywords: Mangrove Forest Area of Tugurejo, Environmental Management, Commuunity Participation

\section{Pendahuluan}

Kawasan Hutan Mangrove Tugurejo (KHMT) memiliki potensi dan keunikan sumber daya alam yang seyogianya dapat dimanfaatkan secara optimal, bijaksana, dan berkelanjutan demi tercapainya kesejahteraan masyarakat Kota
Semarang pada umumnya dan masyarakat pesisir Kota Semarang pada khususnya, baik bagi generasi sekarang maupun bagi generasi yang akan datang, serta tetap terjaminnya kelestarian SDA di wilayah pesisir itu sendiri. Pemanfaatan dan pelestarin KHMT dalam upaya mendukung pengembangan wilayah pesisir Kota Semarang 
harus mempertimbangkan tiga aspek keberlanjutan, yang meliputi aspek ekonomi, sosial, dan lingkungan atau ekologi. Ketidakserasian dalam pengelolaan ketiga aspek keberlanjutan tersebut dapat berdampak negatif terhadap salah satu aspek diantaranya, aspek lingkungan terkadang dan bahkan sering menjadi aspek yang menangung ketidakserasian tersebut.

Wibowo dan Handayani (2006) menjelaskan bahwa dengan semakin meningkatnya pembangunan yang berorientasi pada aspek ekonomi, seperti konversi hutan mangrove menjadi area permukiman, kegiatan perikanan tambak, rekreasi, dan sebagainya telah memberi dampak negatif pada keberadaan ekosistem hutan mangrove. Dahuri dkk (2001) menambahkan bahwa beberapa kegiatan pembangunan di wilayah pesisir yang dapat memberikan dampak terhadap kelestarian lingkungan meliputi pembangunan kawasan permukiman, kegiatan industri, rekreasi dan pariwisata bahari serta konversi hutan menjadi area pertambakan.

Salah satu upaya yang telah dilakukan Pemerintah Kota Semarang dalam mendukung program pengelolaan hutan mangrove di Wilayah Pesisir Tugurejo adalah dengan bekerja sama dengan Mercy Corps, sebuah organisasi nirlaba (LSM) dari Amerika Serikat melalui Program ACCCRN (Asian Cities Climate Change Resilience Network). Pada tahun 2010, sebagai proyek percontohan ACCCRN, di Dusun Tapak, Kelurahan Tugurejo telah dilakukan penanaman tidak kurang dari 20.000 bibit mangrove dan pembuatan tanggul penahan ombak atau lebih dikenal sebagai alat pemecah ombal (APO) yang terbuat dari ban bekas mobil sejauh 120 meter di sepanjang garis pantai wilayah pesisir Tugurejo. Dengan bekerja sama dengan masyarakat Tapak dan Pemerintah Kota Semarang, pada tahun 2011 Program ACCCRN telah menanam lebih dari 285.000 bibit mangrove dan pembuatan APO yang mencapai panjang 785 meter dari panjang 1.900 meter yang dibutuhkan. Pada tahun 2012 ini, sekitar satu miliar rupiah telah diajukan oleh Dinas Kelautan dan Perikanan Kota Semarang untuk membeli sebidang tanah di Tugurejo dari pihak swasta yang akan digunakan untuk mendirikan Pusat Pendidikan Bakau dan Konservasi Berbasis Masyarakat di Tugurejo (Mercy Corps, 2012).
Berdasarkan uraian di atas dapat disimpulkan bahwa diperlukan sebuah kajian mengenai partisipasi masyarakat, sebagai pihak yang berhubungan langsung dengan KHMT, untuk mendukung pengembangan wilayah pesisir Kota Semarang, dengan tujuan untuk memberikan gambaran mengenai partisipasi masyarakat terhadap pengelolaan lingkungan KHMT.

\section{Materi dan Metode}

Penelitian ini berjenis studi kasus dengan menggunakan metode kualitatif dan metode deskriptif. Sugiyono (2009) menjelaskan bahwa berdasarkan tingkat kealamiahan (natural setting), metode kualitatif disebut juga metode naturalistik, yaitu penelitian dilakukan pada tempat yang alamiah dan tidak membuat perlakuan. Metode deskriptif pada penelitian ini bertujuan untuk memberikan gambaran mengenai persepsi dan partisipasi masyarakat dalam pengelolaan lingkungan KHMT.

Penelitian dilaksanakan selama tiga bulan, yaitu bulan Maret sampai dengan bulan Mei 2012. Ruang lingkup materi pada penelitian ini adalah persepsi dan partisipasi masyarakat terhadap pengelolaan lingkungan KHMT serta karakteristik masyarakat Kelurahan Tugurejo yang meliputi tingkat pendidikan dan mata pencaharian. Sedangkan ruang lingkup wilayah pada penelitian ini adalah Kawasan Hutan Mangrove Tugurejo (KHMT) yang secara administratif berada di Wilayah Kelurahan Tugurejo, Kota Semarang, dengan pertimbangan bahwa pada lokasi ini memiliki potensi yang mendukung upaya pengelolaan lingkungan KHMT.

Data yang digunakan meliputi data primer dan data sekunder berdasarkan ruang lingkup penelitian. Data primer berupa persepsi dan partisipasi masyarakat terhadap pengelolaan lingkungan KHMT dan data sekunder berupa gambaran kondisi umum KHMT yang meliputi flora, fauna, dan bentang alam, serta karakteristik masyarakat Tugurejo yang meliputi jumlah dan kepadatan penduduk, mata pencaharian, tingkat pendidikan, mata pencaharian, dan sistem kelembagaan pengelolaan KHMT.

Pemilihan narasumber menggunakan teknik nonprobability sampling dengan metode purposive 
sampling. Narasumber pada penelitian ini meliputi masyarakat, instansi, dan pakar/akademisi yang berjumlah 21 narasumber. Penentuan jumlah narasumber tidak berdasarkan perhitungan statistik (Lincoln dan Guba, 1985 dalam Sugiyono, 2009), namun jumlah narasumber dianggap memadai jika data telah mencapai taraf redundancy (data telah jenuh dan narasumber tidak memberikan informasi yang baru), artinya bahwa dengan menggunakan narasumber selanjutnya boleh dikatakan tidak lagi diperoleh informasi baru yang berarti (Nasution, 1988) dalam Sugiyono, 2009).

Data primer didapatkan secara langsung dengan cara observasi, dokumentasi, wawancara, dan triangulasi dari beberapa objek penelitian. Data sekunder didapatkan secara tidak langsung dengan cara studi literatur terhadap dokumen-dokumen yang berkaitan dengan objek penelitian pada beberapa instansi terkait.

Analisis data dilakukan dengan cara mencari dan menyusun data hasil penelitian secara sistematis, meliputi pengorganisasian data ke dalam kategori, penjabaran ke dalam unit-unit, melakukan sintesis, menyusun ke dalam pola, memilih mana yang penting dan akan dipelajari, dan membuat kesimpulan, sehingga mudah dipahami oleh diri sendiri dan orang lain (Sugiyono, 2009).

\section{Hasil dan Pembahasan}

\section{Kondisi Sosial Ekonomi dan Budaya Masyarakat Kelurahan Tugurejo}

KHMT secara geografis secara geografis berada pada wilayah pesisir Kecamatan Tugu, Kota Semarang. Jumlah penduduk Kelurahan Tugurejo pada akhir bulan Februari 2012 mencapai 6.357 jiwa, dengan kepadatan penduduk mencapai 770 jiwa/km2 (Monografi Kelurahan Tugurejo, Februari 2012). Nilai kepadatan tersebut lebih rendah dari rata-rata kepadatan penduduk Kota Semarang pada tahun 2009 yang mencapai 4.032 jiwa/km2 dan Provinsi Jawa Tengah yang mencapai 994,97 jiwa/km2. Berdasarkan data jumlah penduduk selama lima tahun terakhir (tahun 2004-2009) telah terjadi kenaikan jumlah penduduk dengan rata-rata pertumbuhan (C) 2012, Program Studi Ilmu Lingkungan Program Pasca Sarjana UNDIP penduduk tahunan Kota Semarang yang cukup tinggi, mencapai $1,71 \%$. Dengan kecenderungan naiknya jumlah penduduk di Kota Semarang akan berdampak pada naiknya kebutuhan lahan untuk permukiman, kegiatan usaha, pertanian, perikanan, dan lain-lain. Adanya beberapa dampak dari kenaikan jumlah penduduk tersebut menjadi faktor yang secara langsung maupun tidak langsung dapat memberi pengaruh terhadap kelestarian KHMT.

Berdasarkan data penelitian terlihat bahwa bahwa penduduk yang berprofesi sebagai nelayan sangat sedikit, yaitu 7 orang. Berbagai jenis kegiatan yang dilakukan para nelayan antara lain menangkap ikan dan udang di perairan sekitar kawasan hutan mangrove dengan menggunakan berbagai cara dan alat tangkap, seperti menggunakan jaring rajungan, jaring kantong, cangapan (perangkap udang), dan jala, dengan menggunakan perahu sebagai sarana transportasinya.

Tabel 1. Mata Pencaharian Penduduk Kelurahan Tugurejo

\begin{tabular}{clc}
\hline No. & \multicolumn{1}{c}{ Mata Pencaharian } & Jumlah Penduduk \\
\hline 1 & Petani & 73 \\
\hline 2 & Buruh Tani & 202 \\
\hline 3 & Nelayan & 7 \\
\hline 4 & Pengusaha & 1 \\
\hline 5 & Buruh Industri & 1085 \\
\hline 6 & Buruh Bangunan & 201 \\
\hline 7 & Pedagang & 166 \\
\hline 8 & Pengangkutan & 73 \\
\hline 9 & Pegawai (Sipil, TNI, dan Polisi) & 384 \\
\hline 10 & Pensiunan & 36 \\
\hline 11 & Lain-lain & 2805 \\
\hline \multicolumn{2}{c}{ Jumlah } & 5033 \\
\hline Sumber: Monografi Kelurahan Tuqurejo, Februari 2012
\end{tabular}

Secara kuantitas, dengan sedikitnya jumlah penduduk yang berprofesi sebagai nelayan, maka menjadi kendala bagi program pengelolaan lingkungan KHMT, namun secara kualitas dengan melihat antusias para penduduk, khususnya penduduk yang telah memilki kepedulian terhadap kelestarian lingkungan wilayah pesisir, yang tergabung dalam kelompok peduli lingkungan Prenjak, Kelompok petani tambak Sido Rukun, dan kelompok nelayan Rukun Makmur di sekitar kawasan hutan mangrove, serta adanya kepedulian dari berbagai instansi pemerintah, swasta, dan berbagai yayasan peduli lingkungan, seperti Bintari, Green Community, dan lain-lain, maka dapat pula faktor ini menjadi sebuah kekuatan 
yang dapat mendukung pengelolaan lingkungan KHMT. Kegiatan yang telah dilakukan oleh beberapa kelompok tersebut antara lain kegiatan penanaman bibit mangrove, pembuatan alat pemecah ombak (APO), pengedukasian masyarakat tentang lingkungan wilayah pesisir, khususnya ekosistem mangrove, yaitu dengan dibentuknya Mangrove Education Center (MEC).

Tingkat pendidikan dapat mempengaruhi bentuk persepsi masyarakat dan bentuk partisipasi masyarakat dalam pengelolaan lingkungan KHMT. Tingkat pendidikan yang cukup baik ini dapat menjadi faktor pendukung dalam proses perencanaan, pelaksanaan, dan bahkan sampai proses evaluasi terhadap program pengelolaan lingkungan KHMT.

Tabel 2. Tingkat Pendidikan Penduduk Kelurahan Tugurejo

\begin{tabular}{|c|c|c|}
\hline No. & Pendidikan & Jumlah Penduduk \\
\hline 1 & Perguruan Tinggi & 151 \\
\hline 2 & Tamat Akademi & 123 \\
\hline 3 & Tamat SLTA & 882 \\
\hline 4 & Tamat SLTP & 715 \\
\hline 5 & Tamat SD & 1861 \\
\hline 6 & TidakTamat SD & 187 \\
\hline 7 & Belum TamatSD & 1334 \\
\hline & TidakSekolah & 276 \\
\hline & Jumlah & 5529 \\
\hline
\end{tabular}

\section{Persepsi dan Partisipasi Masyarakat}

Secara umum dikatakan bahwa masyarakat mengetahui keberadaan KHMT di lokasi studi dan mangatakan bahwa kondisi KHMT sekarang sudah menjadi lebih baik (100\% narasumber).

Persepsi masyarakat terhadap kondisi KHMT diarahkan pada perubahan lingkungan kawasan pesisir Tapak Tugurejo selama periode 10-20 tahun terakhir. Seluruh masyarakat setempat mengatakan bahwa kondisi KHMT dalam periode waktu tersebut menjadi semakin baik. Selain adanya kesadaran lingkungan dari masyarakat setempat, seperti tidak boleh menebang ranting, batang, dan pohon mangrove yang masih hidup dan adanya untuk menjaga dan melestarikan KHMT, yang dapat mempengaruhi pendapatan nelayan dan petani tambak, maka seluruh (C) 2012, Program Studi Ilmu Lingkungan Program Pasca Sarjana UNDIP narasumber berharap adanya upaya perlindungan dan perbaikan KHMT.

Tabel 3. Tingkat Pengetahuan Masyarakat terhadap KHMT $(\mathrm{n}=21)$

\begin{tabular}{clc}
\hline No. & \multicolumn{1}{c}{ Tingkat Pengetahuan } & Persentase (\%) \\
\hline 1 & $\begin{array}{l}\text { Mengetahui bahwa hutan di Wilayah Pesisir Tapak Tugurejo Kota } \\
\text { Semarang merupakan kawasan hutan mangrove. }\end{array}$ & 100 \\
\hline & $\begin{array}{l}\text { Mengetahui manfaat Kawasan Hutan Mangrove Tugurejo sebagai } \\
\text { pelindung pinggir pantai/sungai dari abrasi yang disebabkan oleh } \\
\text { adanya gelombangair laut. }\end{array}$ & 100 \\
\hline & $\begin{array}{l}\text { Mengetahui manfaat Kawasan Hutan Mangrove Tugurejo sebagai } \\
\text { tempat hidup berbagai binatang liar, seperti biawak dan ular serta } \\
\text { berbagai jenis burung. }\end{array}$ & 100 \\
\hline 4 & $\begin{array}{l}\text { Mengetahui manfaat Kawasan Hutan Mangrove Tugurejo sebagai } \\
\text { tempat mencari kayu bakar dan ikan bagi masyarakat setempat. }\end{array}$ & 52 \\
\hline 5 & $\begin{array}{l}\text { Mengetahui manfaat Kawasan Hutan Mangrove Tugurejo sebagai } \\
\text { pelindung berbagai jenis ikan, udang, kerang, kepiting, dan binatang } \\
\text { laut yang hidup di sekitarnya. }\end{array}$ & 100 \\
\hline 6 & $\begin{array}{l}\text { Mengetahui manfaat Kawasan Hutan Mangrove Tugurejo sebagai } \\
\text { penyerap polutan dari limbah cair industri. }\end{array}$ & 90 \\
\hline 7 & $\begin{array}{l}\text { Mengetahui manfaat Kawasan Hutan Mangrove Tugurejo sebagai } \\
\text { penahan angin kencang dan penahan pematang tambak. }\end{array}$ & 100 \\
\hline Sumber: Diarto dkk, 2012 &
\end{tabular}

Dasar persepsi positif terhadap KHMT terbentuk karena pada masyarakat setempat pernah dilakukan kegiatan sosialisasi atau penyuluhan oleh salah satu pihak terkait, seperti instansi pemerintah, lembaga swadaya masyarakat (LSM) lingkungan, dan atau pihak-pihak lain tentang pengelolaan kawasan tersebut.

Tabel 4. Kegiatan Masyarakat pada KHMT $(n=21)$

\begin{tabular}{clc}
\hline No. & \multicolumn{1}{c}{ Jenis Kegiatan } & Persentase (\%) \\
\hline 1 & Mencari ikan, udang, kerang, kepiting, dan binatang laut lainnya. & 62 \\
\hline 2 & $\begin{array}{l}\text { Mencari ranting pohon api-api (Avicenia sp.) untuk memperbaiki } \\
\text { pematang tambak. }\end{array}$ & 52 \\
\hline 3 & Mencari bibit pohon mangrove untuk ditanam kembali. & 62 \\
\hline 4 & Memancing dan atau rekreasi. & 24 \\
\hline 5 & Mencari kayu bakar. & 0 \\
\hline 6 & Mencari buah mangrove untuk dijadikan bahan olahan makanan. & 0 \\
\hline 7 & Identifikasi keanekaragaman hayati/penelitian & 29 \\
\hline Sumber: Diarto dkk, 2012 & \\
\hline
\end{tabular}

Dengan kondisi Kawasan Ekosistem Hutan Mangrove Tugurejo yang semakin baik dan dengan berbagai manfaat yang dimilikinya, banyak masyarakat yang mulai lebih peduli terhadap kawasan ini dengan melakukan berbagai kegiatan di sekitar kawasan ini secara bertanggung jawab. 
Diarto, Boedi Hendrarto, Sri Suryoko. 2012. PARTISIPASI MASYARAKAT DALAM PENGELOLAAN LINGKUNGAN KAWASAN HUTAN MANGROVE TUGUREJO DI KOTA

\section{Kondisi Fisik dan Bentang Alam KHMT}

KHMT diapit dua sungai yang menjadi batas ekologisnya, yaitu Sungai Tapak pada sebelah barat dan Sungai Maron yang berada di sebelah timur kawasan ini. Sebagai sebuah ekosistem yang unik, KHMT berasosiasi dengan ekosistem perairan payau Pesisir Tugurejo. Secara fisik terdiri dari daratan pantai Tugurejo dan kumpulan tanah timbul hasil proses sedimentasi dari Sungai Tapak. Secara ekologis terdiri dari area hutan mangrove, area pertambakan, habitat flora dan fauna, serta area berbagai kegiatan sosial ekonomi dan budaya masyarakat pesisir Tugurejo.

Dari aspek hidrologi, KHMT berbatasan langsung dengan perairan pesisir Tugurejo dan muara Sungai Tapak pada sebelah baratnya. Berbagai komponen lingkungan di atas saling berinteraksi membentuk sebuah kesatuan ekosistem yang unik dan memiliki potensi besar untuk dikembangkan sebagai sumber pendapatan masyarakat pesisir Tugurejo.

\section{Flora dan Fauna KHMT}

Disamping sebagai pelindung garis pantai dan penahan tanggul pada area pertambakan, berbagai jenis flora tersebut juga berperan dalam meningkatkan produktivitas tambak yang berasosiasi dengannya. Oleh karena itu, keberadaan jenis flora tersebut harus tetap diperhatikan untuk menjaga keberlangsungan ekologis hutan mangrove, dengan mempertimbangkan fungsi ekologisnya untuk jangka waktu pendek maupun jangka waktu panjang. Karena berada diperbatasan antara darat dan Iaut, ekosistem hutan mangrove merupakan ekosistem yang kompleks dan saling berasosiasi dengan ekosistem disekitarnya, baik darat maupun lepas pantai.

Berdasarkan tingkat pohon, pada KHMT diperoleh nilai dominansi (D) sebesar 0,80, hal ini menunjukkan bahwa pada kawasan ini terdapat spesies yang mendominasi, yaitu Avicennia marina dengan nilai kerapatan relatif (KR) sebesar 88,9\%. Dasar persepsi positif terhadap KHMT terbentuk karena pada masyarakat setempat pernah dilakukan kegiatan sosialisasi atau penyuluhan (C) 2012, Program Studi Ilmu Lingkungan Program Pasca Sarjana UNDIP oleh salah satu pihak terkait, seperti instansi pemerintah, lembaga swadaya masyarakat (LSM) lingkungan, dan atau pihak-pihak lain tentang pengelolaan kawasan tersebut.

Tabel 5. Hasil Analisis Vegetasi Mangrove untuk Tingkat Pohon

\begin{tabular}{|c|c|c|c|c|c|c|c|c|c|c|}
\hline Spesies & $\begin{array}{l}\text { Jumlah } \\
\text { (ind) }\end{array}$ & $\begin{array}{c}\text { Diameter } \\
(\mathrm{cm})\end{array}$ & $\begin{array}{c}\text { K } \\
\text { (ind/ha) }\end{array}$ & $\begin{array}{c}\mathrm{BA} \\
\left(\mathrm{cm}^{2}\right)\end{array}$ & $\begin{array}{l}\text { KR } \\
(\%)\end{array}$ & $\begin{array}{l}\text { DR } \\
(\%)\end{array}$ & $\mathrm{NP}$ & $H^{\prime}$ & $\mathrm{J}^{\prime}$ & $D$ \\
\hline $\begin{array}{l}\text { Rhizophora } \\
\text { mucronata }\end{array}$ & 3 & 8,505 & 100 & 56,8 & 11,1 & 55,7 & 66,8 & & . & . \\
\hline $\begin{array}{l}\text { Avicennia } \\
\text { marina }\end{array}$ & 24 & 7,585 & 800 & 45,2 & 88,9 & 44,3 & 133,2 & . & . & $\cdot$ \\
\hline Jumlah & 27 &. & 900 & 101,9 & 100 & 100 & 200 & 0,15 & 0,02 & 0,80 \\
\hline
\end{tabular}

Keterangan:
$\mathrm{K}$ = Kerapatan
$\mathrm{BA}=$ Basal Area
$\mathrm{KR}=$ Kerapatan Relatif
DR = Dominansi Relatif
$\mathrm{H}^{\prime}$ = Indeks Keanekaragaman
J' = Indeks Keseragaman
$\mathrm{D}=$ Indeks Dominansi
$\mathrm{NP}=$ Nilai Penting

Berdasarkan tingkat anakan, pada KHMT diperoleh nilai D sebesar 0,67, didominasi oleh spesies Rhizophora mucronata dengan nilai KR sebesar 81,1\%. Dan berdasarkan tingkat semai, pada KHMT diperoleh nilai D sebesar 0,72, didominasi oleh spesies Avicennia marina dengan nilai KR sebesar 83,3\%.

Berdasarkan Kriteria Baku Kerusakan Mangrove, dengan melihat Nilai Kerapatan, vegetasi mangrove di KHMT untuk tingkat pohon pada jenis Rhizophora mucronata dan Avicennia marina dalam kondisi jarang, untuk tingkat anakan pada jenis Rhizophora mucronata dalam kondisi sangat padat dan pada jenis Excoecaria agallocha, Lumnitzera racemosa, dan Avicennia marina dalam kondisi jarang, sedangkan untuk tingkat semai pada jenis Rhizophora mucronata dan Avicennia marina dalam kondisi sangat padat. Maka, dapat dikatakan bahwa jenis Rhizophora mucronata dan Avicennia marina lebih mampu beradaptasi pada kawasan ini. 
Tabel 6. Kriterian Baku Kerusakan Mangrove

\begin{tabular}{|c|c|c|c|}
\hline & Kriteria & Penutupan (\%) & Kerapatan (ind/ha) \\
\hline \multirow{2}{*}{ Baik } & Sangat Padat & $\geq 75$ & $\geq 1.500$ \\
\hline & Sedang & $\geq 50-<75$ & $\geq 1.000-<1.500$ \\
\hline Rusak & Jarang & $<50$ & $<1.000$ \\
\hline
\end{tabular}

Berdasarkan hasil analisis fauna pada KHMT diperoleh nilai indeks keanekaragaman $\left(\mathrm{H}^{\prime}\right)$ sebesar 3,09 yang menunjukkan bahwa pada kawasan ini mampu menyediakan sumber daya makanan yang cukup maupun tempat tinggal yang dibutuhkan oleh burung, hal ini menyebabkan keanekaragaman burung akan cenderung menjadi lebih tinggi. Bagi satwa liar secara umum habitat berfungsi sebagai tempat hidup untuk mencari makan, minum, istirahat, dan berkembangbiak, sehingga habitat yang beragam tentu memiliki beragam penyedia kebutuhan bagi satwa liar, sehingga makin banyak satwa liar yang hadir pada kawasan ini disebabkan oleh banyaknya kebutuhan makanan dan habitat tempat tinggal yang tersedia didalamnya. Nilai indeks keseragaman (J') sebesar 0,85 yang menunjukkan bahwa penyebaran jenis burung sangat merata dengan kata lain suatu jenis burung hampir dapat ditemukan pada seluruh area pertambakan di KHMT ini. Rahayuningsih dkk (2006) menjelaskan bahwa kelimpahan masing-masing jenis burung dalam suatu komunitas tidaklah sama, sehingga terkadang terdapat beberapa jenis yang mendominasi atau lebih sering dijumpai pada suatu komunitas tertentu. Bagi jenis burung tertentu yang memiliki kelimpahan yang sangat besar diakibatkan karena jenis ini memiliki jumlah individu, biomasa, serta nilai penting yang besar, sehingga mendominasi suatu komunitas tertentu dan biasanya memiliki nilai dominansi yang tinggi juga.

Berdasarkan keanekaragaman dari berbagai jenis burung, secara keseluruhan dapat dikatakan bahwa KHMT dengan segala komponen lingkungan yang berasosiasi didalamnya merupakan habitat yang baik bagi berbagai burung dalam memenuhi segala aspek kelangsungan hidupnya yang meliputi penyediaan makanan, tempat tinggal, dan sebagai tempat perkembangbiakan.

\section{Sistem Kelembagaan Pengelolaan}

Secara administratif kelembagaan, keberadaaan Kawasan Hutan Mangrove Tugurejo berada di bawah pengelolaan Dinas Kelautan dan Perikanan Kota Semarang. Dalam pelaksanaannya, terkait dengan program perencanaan, pelaksanaan, dan evaluasinya masih terdapat beberapa kendala, seperti adanya tumpang tindah antara beberapa pelasanaan program di wilayah pesisir Kota Semarang, khususnya berkaitan dengan pengelolaan mangrove. Adanya kendala tersebut memunculkan inisiatif dari beberapa instansi Pemerintah Kota Semarang yang terkait dengan pengelolaan mangrove, seperti Dinas Kelautan, Dinas Pertanian, Badan Lingkungan Hidup, dan Badan Perencanaan Pembangunan Daerah Kota Semarang untuk membentuk sebuah lembaga khusus yang menangani masalah pengelolaa mangrove di Kota Semarang, yaitu Kelompok Kerja Mangrove Kota Semarang (KKMKS), sebuah lembaga yang diharapkan dapat mengakomodasi tanggung jawab berbagai instansi tersebut dalam melestaikan wilayah pesisir Kota Semarang.

Terdapat beberapa kelompok/perkumpulan masyarakat dan atau lembaga swadaya masyarakat (LSM) lingkungan yang terpadu dan sinergi dalam pelaksanaan kegiatan pengelolaan Kawasan Hutan Mangrove Tugurejo. Sedangkan kegiatan sosialisasi atau penyuluhan tentang pengelolaan Kawasan Hutan Mangrove Tugurejo bagi bagi masyarakat setempat telah sering dilakukan oleh semua pihak, namun kegiatan tersebut belum terprogram dan terjadwal dengan baik. Sebagai sebuah kawasan yang secara langsung berbatasan dengan perairan laut, maka kawasan ini memerlukan sebuah upaya pengaman dari seluruh pihak terkait untuk mencegah terjadinya gangguan atau bahkan kerusakan lingkungan disekitarnya. Secara keseluruhan, upaya pengamanan di kawasan ini telah dilakukan oleh semua pihak, namun kegiatan tersebut belum terprogram dan terjadwal dengan baik (71\% narasumber).

\section{Kesimpulan}

Dengan tingkat pendidikan yang cukup baik dan terbentuknya persepsi masyarakat yang positif terhadap KMTH telah memberikan pengaruh 
Diarto, Boedi Hendrarto, Sri Suryoko. 2012. PARTISIPASI MASYARAKAT DALAM PENGELOLAAN LINGKUNGAN KAWASAN HUTAN MANGROVE TUGUREJO DI KOTA

http://ejournal.undip.ac.id/index.php/ilmulingkungan

terhadap partisipasi masyarakat terhadap pengelolaan lingkungan KHMT, yang ditunjukkan dengan tingginya keinginan masyarakat untuk menjaga, melestarikan, dan mengharapkan adanya upaya perlindungan dan perbaikan KHMT. Bentuk partisipasi masyarakat adalah sukarela, yaitu dengan kegiatan rutin mereka, seperti melakukan perbaikan tambak. Dengan adanya kepedulian lingkungan masyarakat setempat terhadap KHMT, maka dapat dikatakan bahwa bentuk partisipasi masyarakat adalah manajemen sendiri (self management), karena terbentuk dengan sendirinya atas kesadaran lingkungan masyarakat setempat.

\section{Ucapan Terima Kasih}

Penulis mengucapkan terima kasih yang sebesarbesarnya atas dukungan, arahan, dan bimbingan yang telah diperoleh dalam penyelesaian penelitian ini kepada Yth.:

1. Kepala Biro Perencanaan dan Kerja Sama Luar Negeri, Kementerian Pendidikan dan Kebudayaan (Kemendikbud) selaku pemberi pemberi Beasiswa Unggulan pada penulis.

2. Masyarakat Dukuh Tapak, Kelurahan Tugurejo, Kota Semarang yang telah memberikan informasi yang dibutuhkan dalam penelitian ini.

3. Pimpinan SKPD di lingkungan Pemerintah Kota Semarang yang telah memberikan informasi dan data yang dibutuhkan dalam penelitian ini.

4. Semua pihak yang telah membantu dalam penyelesaian penelitian ini yang tidak dapat saya sebutkan namanya satu persatu.

\section{Daftar Pustaka}

Dahuri, R., Rais, Y., Putra, S.G., Sitepu, M.J., 2001. Pengelolaan Sumber Daya Wilayah Pesisir dan Lautan secara Terpadu. Pradnya Paramita. Jakarta.

Diarto, Hendrarto, B., Suryoko, S., 2012, Strategi Pengembangan Wanamina pada Kawasan Hutan Mangrove Tugurejo di Kota Semarang. Prosiding Seminar Nasional Pengelolaan Sumber Daya Alam dan Lingkungan. Program Pascasarjana Ilmu Lingkungan. Universitas Diponegoro. Semarang.
Mercy Corps, 2012. Proyek Percontohan ACCCRN di Desa Tugurejo, Semarang, Indonesia. Http://indonesia.mercycorps.org/

Keputusan Menteri Negara Lingkungan Hidup Nomor 201 Tahun 2004 tentang Kriteria Baku dan Pedoman Penentuan Kerusakan Mangrove. Kantor Sekretariat Negara Republik Indonesia. Jakarta.

Rahayuningsih M., B. Priyono, dan A.S. Nugroho., 2006. Keanekaragaman Jenis Burung di Pulau Galeang-Taman Nasional Karimunjawa. Prosiding Seminar Nasional Biologi. Jurusan Biologi. FMIPA. Universitas Negeri Semarang. Semarang.

Sugiyono, 2009, Metode Penelitian Kuantitatif, Kualitatif, dan R\&D. Alfabeta. Bandung.

Wibowo, K. dan Handayani, T., 2006. Pelestarian Hutan Mangrove melalui Pendekatan Mina Hutan (Silvofishery). Jurnal Teknik Lingkungan., 7 (3): 135-137. 